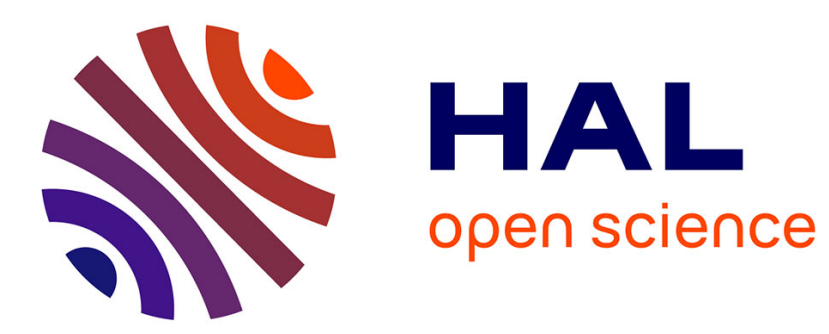

\title{
Modal parameter variability in industrial electric guitar making: Manufacturing process, wood variability, and lutherie decisions
}

\author{
Arthur Paté, Jean-Loic Le Carrou, Benoît Fabre
}

\section{- To cite this version:}

Arthur Paté, Jean-Loic Le Carrou, Benoît Fabre. Modal parameter variability in industrial electric guitar making: Manufacturing process, wood variability, and lutherie decisions. Applied Acoustics, 2015, 96, pp.118-131. 10.1016/j.apacoust.2015.03.023 . hal-01148234

\section{HAL Id: hal-01148234 \\ https://hal.sorbonne-universite.fr/hal-01148234}

Submitted on 4 May 2015

HAL is a multi-disciplinary open access archive for the deposit and dissemination of scientific research documents, whether they are published or not. The documents may come from teaching and research institutions in France or abroad, or from public or private research centers.
L'archive ouverte pluridisciplinaire HAL, est destinée au dépôt et à la diffusion de documents scientifiques de niveau recherche, publiés ou non, émanant des établissements d'enseignement et de recherche français ou étrangers, des laboratoires publics ou privés. 


\title{
Modal parameter variability in industrial electric guitar making: manufacturing process, wood variability, and lutherie decisions
}

\author{
Arthur Patéa ${ }^{a, b}$, Jean-Loïc Le Carrou ${ }^{\mathrm{a}, \mathrm{b}}$, Benoît Fabre ${ }^{\mathrm{a}, \mathrm{b}}$ \\ ${ }^{a}$ Sorbonne Universités, UPMC Univ Paris 06, UMR 7190, Institut Jean Le Rond \\ d'Alembert, équipe LAM, 11, rue de Lourmel, F-75015 Paris, France, email: \\ pate@lam.jussieu.fr \\ ${ }^{b}$ CNRS UMR 7190, Institut Jean Le Rond d'Alembert, équipe LAM, 11, rue de Lourmel, \\ F-75015 Paris, France
}

\begin{abstract}
Recent studies showed that mechanical coupling between structure and strings can alter the sound of the solid body electric guitar. Modal frequencies and damping ratios of the structure can explain some sound differences between instruments. These vibratory parameters can vary because of lutherie decisions (e.g. intentionally fitting guitars with different woods for sound quality purposes), wood intrinsic variability, or making process variability. Yet the vast majority of solid body electric guitars comes from an industrial massproduction: the manufacturing process is designed for producing guitars that are the most similar possible. However, musicians and makers know that guitars of the same model both share features, and still have some individual properties. The experimental quantification of the modal parameter variability of nominally identical electric guitars in an industrial context is the aim of this article. This variability is assessed on one guitar set, and compared to other industrial objects. A second guitar set is investigated: it consists of guitars with maple or rosewood fingerboard, all other specifications being identical. This second set allows the comparison between making process and wood variability, with the variability due to an intentional lutherie decision: the change of the fingerboard wood.
\end{abstract}

Keywords: electric guitar, vibratory measurements, industrial manufacturing, unit-to-unit variability, lutherie 43.75.Gh, 43.75.Yy, 43.40.At 


\section{Introduction}

The sound of the solid body electric guitar comes from the string velocity signal which is captured by the electromagnetic pickup, and sent through an electro-acoustical chain basically made of signal processing devices (effect pedals), an amplifier, and a loudspeaker for the sound radiation [1]. Without reconsidering the importance of the electro-acoustic chain, it is reasonable to think that the mechanical behaviour of the string has an influence upon the sound of the solid body electric guitar. Even if the structure of the instrument has been designed to avoid vibrations (the "solid" body overcomes feedback problems occuring with high-volume amplification), it is still found to vibrate. Strings and structure constitute a mechanically coupled system.

The string/structure coupling has been studied for various string instruments $[2,3,4,5]$. For the special case of the solid body electric guitar, Fleischer $[6,7]$ showed that the string/structure coupling is well described by the driving-point conductance value at the fretting point on the neck. A model allowing a prediction of decay time and timbre change effects from the knowledge of the conductance has been recently proposed [8]. The coincidence between a string playing frequency and a structure resonance may provoke a great energy transfer from the string to the structure. The resonance of the corresponding string partial is altered, causing decay time or timbre changes. The study of the modal basis of the solid body electric guitar therefore makes sense: modal frequencies control the conductance peak positions, and modal damping ratios control the spread of the conductance peak, so the chance of coupling.

The solid body electic guitar is the first musical instrument in history to have been originally designed for a mass-production: even if numerous craftsmen have gained a solid reputation among the guitar player community, the solid body electric guitar market has been dominated by the industry for over sixty years. In this context, the question of unit-to-unit vibratory behaviour variability deserves to be explored, since some guitar players claim they can notice differences between nominally identical solid body electric guitars.

Even if their making process is highly standardised, mass-produced musical instruments can present notable differences that can be measured physically or psychologically $[9,10,11,12]$. However, to the knowledge of the authors, no study covering a large scale of nominally identical musical instruments has been undertaken so far. Such investigations are a particular lack in the context of the solid body electric guitar. Industrial research 
has been interested in quantifying the uncertainties in the vibro-acoustical behaviour of industrial products. Indeed, it is a well-known fact that nominally identical products present variations, in particular in their vibratory behaviour [13]. It is also known that small variations in geometry or in assembly can lead to large variations in the final product's vibratory behaviour [14]. The aim of variability studies in an industrial context is often to numerically predict the vibro-acoustic behaviour of some mass-produced products $[15,16,17]$. Experimental studies are reported, for example for acoustic noise in cars originating from vibratory phenomena $[18,19]$. Some studies focused on the unit-to-unit variability of industrially-made nominally identical products: wind turbine blades [20] or automotive brake calipers [21] for example.

In the case of the solid body electric guitar, the variability in modal parameters can have different sources, such as the wood intrinsic variability, the industrial making process (machine tolerance, geometrical uncertainties, etc.), the lutherie decisions (different lutherie parameters, e.g. the wood of the fingerboard). The lutherie decisions and their influence on the modal behaviour have been previously investigated. In [22] it was shown that different wood species for the body control differently the torsional behaviour of the neck. Another study observed different vibratory behaviours that may be related to different neck-to-body junctions [23]. The difference between ebony and rosewood fingerboard has been mechanically quantified [24] in terms of mean conductance value over the low- and mid-frequency range.

This article aims at experimentally quantifying the modal parameter (frequency and damping) variability of nominally identical electric guitars in an industrial context. This variability is assessed on one set of 17 guitars, and takes into account the intrinsic variability of nominally identical wood species, and the variability due to the industrial making process. A second set of 24 guitars is investigated: it consists in 10 guitars with a maple fingerboard and 14 guitars with a rosewood fingerboard, all other specifications being nominally identical. This second set is used to compare the variability due to the industrial making process and intrinsic variability of nominally identical woods, with the variability due to an intentional lutherie decision: the change of the fingerboard wood.

Section 2 deals with the description of the experimental material and method, as well as the vibratory measurement analysis method. The identified modal frequencies and damping ratios are presented in section 3 . These results are then discussed in section 4: the unit-to-unit variability observed for electric guitars is compared to that observed for other industrial prod- 
ucts. Then a comparison of modal parameter variability due to the making process (including wood selection) with that due to an intentional lutherie decision is proposed, using two particular guitar sets.

\section{Experimental method}

This section explains the experimental protocol and analysis method carried out on the guitars described in paragraph 2.1: the driving-point mobility is measured on each guitar (paragraph 2.2), and the modal parameters are identified from these measurements (paragraph 2.3).

\subsection{The guitars of the study}

The unique opportunity of measuring industrially-made electric guitars in large number has been given by one of the world's leaders in the solid body electric guitar market: this North-American produces more than 50,000 electric guitars a year, which are sold all around the world. The guitars measured in this study come from the warehouse of this manufacturer and are either in transit from the factory to the music stores, or sent back by customers for small aesthetic defects (wrong colour or varnish). In any case, the measured instruments are ready-to-play guitars meeting the specifications and expected quality standards of the brand. Two distinct sets of guitars are investigated, each of them corresponding to one of the two reference models that are classically thought to organise the electric guitar as an instrument, in an organological sense [1]: Type-1 is a Gibson Les Paul-like instrument, and Type-2 is a Stratocaster-like instrument. Here is a more precise description of the two investigated models:

the Type-1 set: three versions of the model are available: the only intentional difference are the magnetic pickups mounted on the guitars. The size of the pickups, hence of the corresponding hollows in the body, is very similar. From the mechanical point of view, these guitars are therefore nominally identical. A mahogany neck with a $62.9 \mathrm{~cm}$-scale length is glued to a mahogany body with maple top and single cutaway. Headstock and body are virtually symmetrical. The fingerboard is made of rosewood. Measurement are performed on 17 specimens of this model.

the Type-2 set: two versions of the model are available. The baseline guitar is common to the two models: a maple neck with a scale-length of 
$64.75 \mathrm{~cm}$ is screwed to a maple body with double cutaway. Headstock and body are strongly asymmetrical. Type-2 guitars are further split into two groups, depending on the fingerboard wood: 10 guitars have a rosewood fingerboard, and 14 have a maple fingerboard. The former are denoted $R N$, and the latter are denoted $M N$, the designations rosewood $\underline{n} e c k$ or $\underline{m}$ aple $\underline{n} e c k$ being inaccurate but usual in electric guitar making language. For clarity reasons, the terms Type-2 $R N$ and Type-2 $M N$ will be replaced by the terms $R N$ and $M N$ in the following of this article.

\subsection{Measurement protocol}

Two kinds of measurements are carried out on each guitar. First the guitar is weighed with the industrial weighing scale avaiblable at the warehouse. This scale has a $10 \times 10^{-3} \mathrm{~kg}$ precision.

Vibratory measurements are then performed. They consist in classic transfer function measurements on the structure. In order to avoid the unwanted string vibration, the strings are damped with felt during the measurements. The guitar is laid on a frame onto which elastic straps are attached. This provides boundary conditions close to free conditions above $20 \mathrm{~Hz}$, which is the upper limit for rigid body modes due to the supporting structure. It was checked that no additional damping was provided by the supporting structure. An impact hammer (PCB Piezotronics 086C01) provides an excitation force $f(t)$ to the structure, and the acceleration response $a(t)$ of the instrument is measured with an accelerometer (PCB Piezotronics 352C65) attached with wax to the structure. In order to not unstring the guitars for the measurements on the neck, the strings are slightly moved aside by a thin and light piece of wood, in order to provide enough space for the hammer to hit the neck without touching the strings [24]. The acceleration signal is integrated, providing the velocity signal $v(t)$ of the structure. A Fourier transform of the force and velocity signals is done, giving a transfer function classically defined as the mobility:

$$
Y(\omega)=\frac{V(\omega)}{F(\omega)}
$$

where $\omega$ is the angular frequency. The energy transfer between string and structure is described by the driving-point conductance $[2,6,7,8]$. The 
conductance $C(\omega)$ is the real part of the mobility:

$$
C(\omega)=\Re(Y(\omega))=\Re\left(\frac{V(\omega)}{F(\omega)}\right)
$$

Figure 1 a presents the driving point conductance measured on the neck of one of the Type-2 guitars. For comparison purposes, the conductance measured at the bridge is plotted with a gray line: the bridge conductance can be neglected in a first approach [8]. Magnitude and phase of the corresponding measurement are shown in figures $1 \mathrm{~b}$ and c respectively. The driving-point condition is obtained by excitating the structure with the hammer as close as possible to the measurement point. The co-location is then checked with the mobility phase values, that stay in the range $[-\pi / 2: \pi / 2]$ in case of driving-point mobility measurements [25]. This is confirmed in figure $1 \mathrm{c}$. 

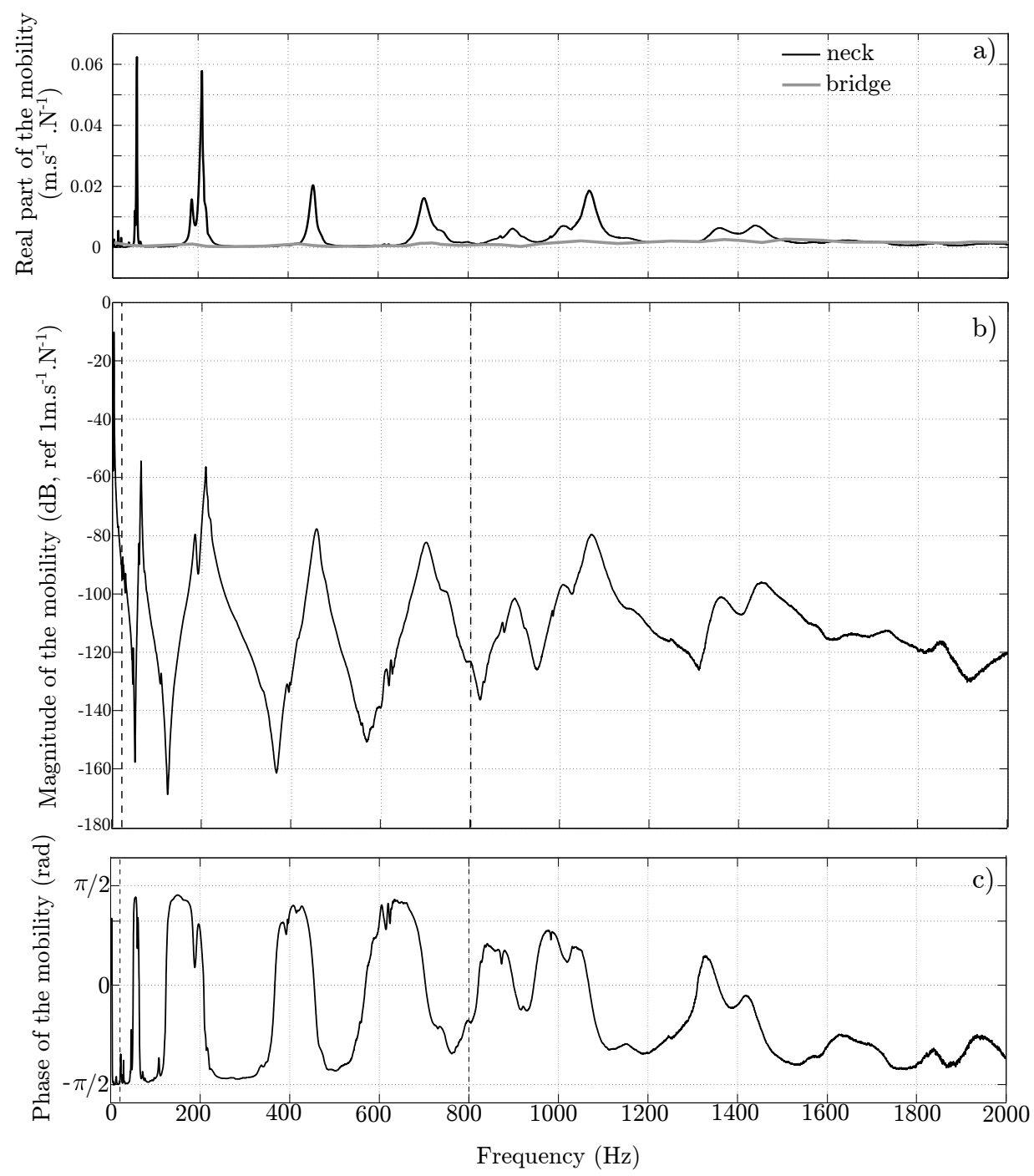

Figure 1: Driving point mobility measurement on the neck of one Type-2 guitar. a) Real part (conductance, in $\mathrm{m} \cdot \mathrm{s}^{-1} \cdot \mathrm{N}^{-1}$ ), for comparison purposes, the gray line presents the conductance measured at the bridge. b) Magnitude in $\mathrm{dB}$ scale normalised to $1 \mathrm{~m} \cdot \mathrm{s}^{-1} \cdot \mathrm{N}^{-1}$. c) Phase. The thick black dashed lines indicate the frequency bandwidth of the study [20 Hz: $800 \mathrm{~Hz}]$.

End-of-chain measurements are aimed to be quick and non-damaging, particularly in the present case, where the investigated objects are guitars about to be shipped to music stores. The non-damaging constraint is ad- 
dressed with the use of a soft head for the hammer. In order to check the repeatability and the frequency bandwidth of our measurement with such a hammer, preliminary measurements on one neck were done. Figure 2c shows the mean excitation of 10 measurements: the excitation spectrum no longer contains enough energy above roughly $800 \mathrm{~Hz}$. Note that this is a typical result otained for our measurements. Figure $2 \mathrm{~b}$ shows the coherence function computed from those 10 preliminary measurements. Above approximately $800 \mathrm{~Hz}$, the coherence values start to move away from 1, indicating a lack of reliability of the measurements above this frequency. Furthermore, the modal overlap seems to become more significant starting from approximately this frequency, as figure 2a shows, and as was also noticeable in figure 1a The bandwidth of the study is then limited to an upper bound of $800 \mathrm{~Hz}$. The frequency bandwidth of the study is finally $[20 \mathrm{~Hz}: 800 \mathrm{~Hz}]$. Note that upper frequencies would be naturally relevant for the study of the string/structure coupling and its eventual influence on the sound, but it would have required another measurement protocol, which might have involved harder hammer tips: such a solution was forbidden by the constraint of not damaging the guitars. 

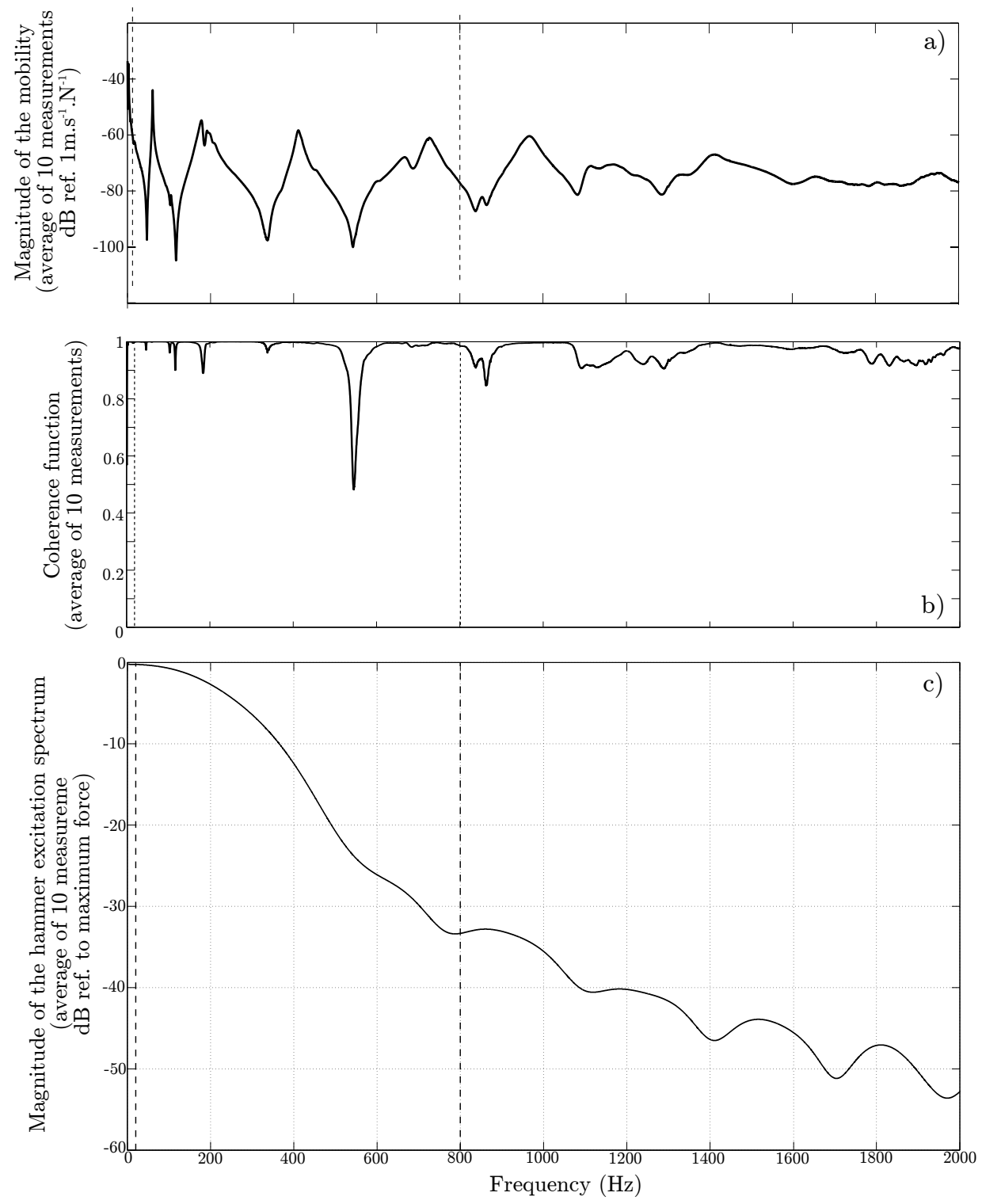

Figure 2: a) Magnitude of the mobility, averaged on 10 measurements. b) Coherence function, computed from 10 measurements. c) Magnitude of the hammer excitation spectrum, averaged on 10 measurements. The thick black dashed lines indicate the frequency bandwidth of the study $[20 \mathrm{~Hz}-800 \mathrm{~Hz}]$.

The issue of measurement rapidity is addressed by the restriction to only one measurement point. However, the selection of this point is not trivial: 
its location has to avoid the coincidence with the nodes of the modes in the frequency range of interest. A preliminary modal analysis is required both for the selection of the measurement point and for interpreting the driving-point measurements. Modal analysis methods are described in section 2.3.

\subsection{Modal parameter identification}

This section describes the modal analysis methods that are used in this study. First (section 2.3.1) the preliminary modal analysis on an experimental mesh is described, and then the method used for the driving-point measurement analysis is detailed (section 2.3.2).

\subsubsection{Preliminary measurements on a mesh}

It was possible to undertake a thorough study of one Type-1 guitar and one Type-2 guitar (assumed was that different fingerboard woods do not change the modes' order of appearance, and that they induce small modal frequency changes). A modal analysis is carried out on these two guitars: transfer functions are measured on an experimental mesh (47 measurement points for the Type-1, 51 measurement points for the Type-2), and then analysed with the least-square complex frequency (LSCF) method implemented in the software MODAN [26]. Experimental meshes are shown in figures 3 and 4 .
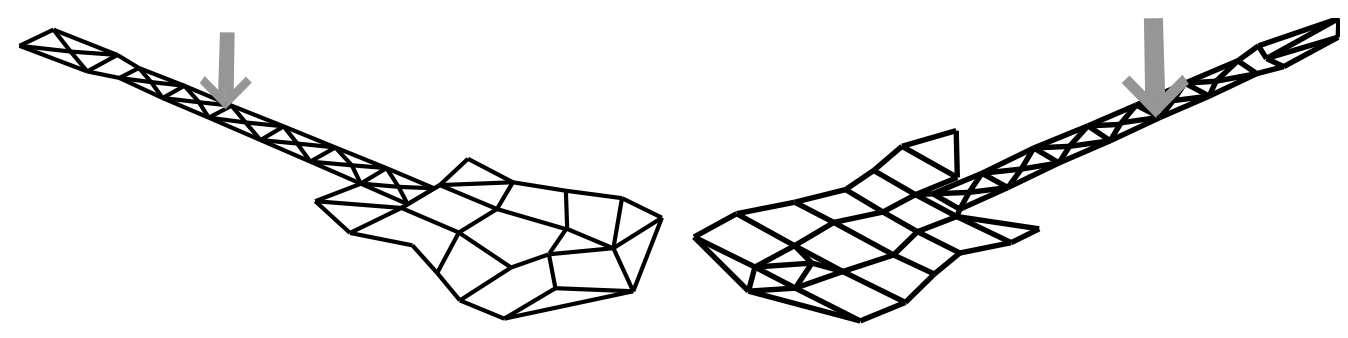

Figure 3: Mesh used for the modal anal- Figure 4: Mesh used for the modal analysis of the Type-1 guitar. The gray ar- ysis of the Type-2 guitar. The gray arrow indicates the measurement point for row indicates the measurement point for the driving-point mobility measurement. the driving-point mobility measurement.

In order to assert the validity of a modal identification, the measured and synthesised frequency response functions are usually compared. Figure 5 
shows an example of such a comparison between measured accelerance (ratio in the frequency domain between the acceleration of the structure and the excitation force) and synthesised accelerance, for the example of the sample Type-1 guitar.
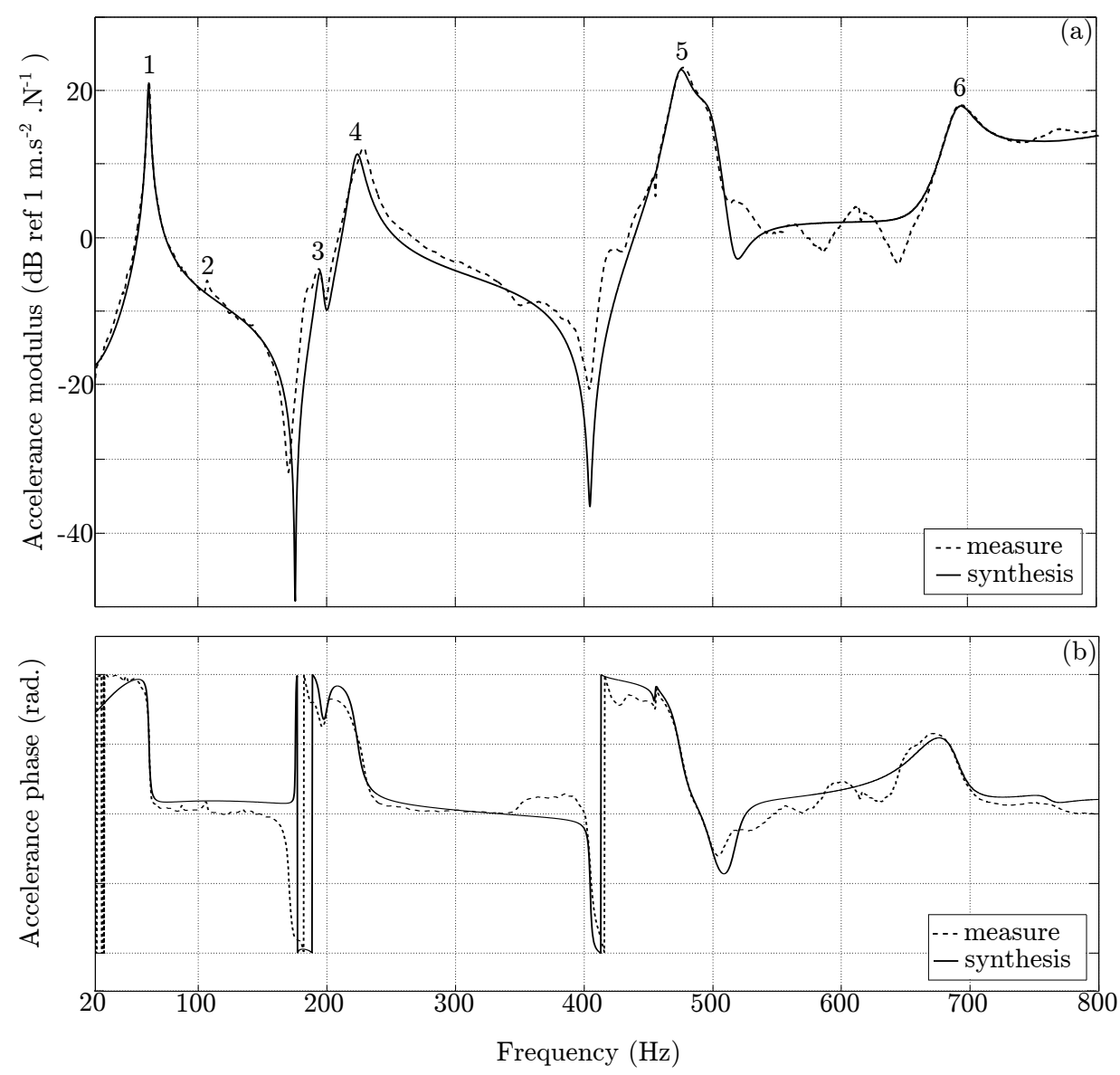

Figure 5: Sample Type1 guitar (tendencies are the same for the sample Type 2 guitar): modal identification with the LSCF method implemented in the software MODAN. (a) modulus, (b) phase. The dashed line curve is the measured accelerance, the solid line curve is the synthesised accelerance. A mode numbering is indicated. The mode 2 is identified separately. The mode near $500 \mathrm{~Hz}$ is a mode that does not involve the neck, so it is not numbered.

Figure 5 is a typical example of a modal identification performed by MODAN. The dashed line curve is the measured accelerance, the solid line 
curve is the synthesised accelerance after modal identification with the LSCF method. No satisfactory identification could be done for the highly-damped peaks at $420 \mathrm{~Hz}$ and between $520 \mathrm{~Hz}$ and $650 \mathrm{~Hz}$. The mode near $100 \mathrm{~Hz}$ is identified when running the LSCF algorithm over a reduced frequency range centered around the accelerance peak. The mode at $520 \mathrm{~Hz}$ is a body mode, according to measurements at the bridge, and can not be well identified with analysis of neck measurements. However, according to $[6,7,8]$, the vibratory study of the bridge is of second importance in the case of the electric guitar. Some unevennesses on the measured accelerance curve can be noticed and attributed to "parasitic" vibrations, like those of the strings or pegs, that have not been removed in order to keep the adjustment made by the luthiers. No additional information would be given by the showing of the same kind of measurement/synthesis comparison for the sample Type-2 guitar: exactly the same phenomena are acting, observed, and identified.

Good agreement is found between the measured and the synthesised accelerances for the identified modes of the sample Type-1 and Type-2 guitars. The modes are therefore well identified and reliable. The results of this preliminary modal analysis are presented in section 3.1. They give the knowledge of the modal shapes, that allows to select the measurement point for the driving-point measurement described in section 2.3.2.

\subsubsection{Driving-point measurement and analysis method}

Since the string/structure coupling occurs mainly on the neck $[6,7,8]$, the measurement point should be located on the neck. A close look at the mode shapes of tables 1 and 2 shows that some points on the neck never coincide with nodes of structure modes. Measurements at such points allow to get information about all the modes of the frequency bandwidth of the study. The measurements points that are chosen are: at the intersection between fret 4 (resp. fret 5) and 1st string axis for the Type-1 (resp. Type-2) model. These points are shown in figures 3 and 4 . A driving-point measurement is carried out on every guitar of each of the two sets, at the corresponding measurement point.

In order to allow for a quantitative comparison of guitars belonging to the same set, this paper proposes to focus on the modal frequencies and dampings. The musical acoustics context of this study is the string/structure coupling and its influence on the sound. The structure conductance (real part of the mobility) value is responsible for the additional string damping leading to decay time or timbre problems, but such coupling effects arise only in 
case of coincidence between the string playing frequencies and the structure modal frequencies [24]. That is to say, the chance of coupling depends on the location of conductance peaks (structure modal frequencies) and on the spread of those conductance peaks (structure modal damping). Therefore the present article particularly focuses on the modal frequencies and modal damping ratios. Modal amplitudes are not investigated here. They have been nevertheless proven by [3] to have an influence on the string/structure coupling: a future study should investigate the modal amplitudes of the structure together with those of the strings in order to compute Gough's coupling indicator.

Modal frequencies and damping ratios are global parameters, that is to say they can be obtained from velocity measurements (mobility), as well as acceleration (accelerance) measurement for example. Furthermore, the hammer excitation force has a smooth spectrum in the frequency bandwidth of the study, so that the acceleration signal can be said to represent the impulse response of the structure without being normalised by the input force. Assuming that the excitation force is small enough to stay in a linear approximation, the acceleration signal can be written as [25]:

$$
a(t)=\sum_{k=1}^{N} a_{k} \sin \left(2 \pi f_{k} t+\phi_{k}\right) e^{-2 \pi f_{k} \xi_{k} t}
$$

where $a_{k}, f_{k}, \phi_{k}$, and $\xi_{k}$ are respectively the modal amplitude, frequency, phase, and damping ratio of mode $k$. Equation 3 tells that the vibratory response of the structure can be modelled as a sum of damped sinusoids. This suggests the use of the ESPRIT method [27] for the identification of modal parameters. The ESPRIT method has already been successfully used for modal parameter identification from structural measurements of string music instruments [28, 29].

In practice, a 2-s long portion of the acceleration signal is analysed, starting $0.1 \mathrm{~s}$ after its onset time, in order to avoid the attack transient effects. The signal portion is filtered around the modal frequency of interest. The filtered signal is then multiplied by a complex exponential at the frequency of interest, in order to get the corresponding spectrum centered around this frequency. Next the result is highly decimated in order to reduce the computation time. This signal is finally analysed with the ESPRIT method. This procedure is repeated for each modal frequency and each measurement. More details are given in $[8,30]$. Identified modal frequencies $f$ and damping ra- 
tios $\xi$ are the focus of the following of this article. The results of the modal parameter identification are given in section 3 .

\section{Results}

This section gives the results of the measurements: modal parameters (shapes, frequencies, and damping ratios) and masses. These results are discussed in section 4

\subsection{Modal parameters of the first two guitars}

This paragraph presents the results of the modal analysis on the experimental mesh described in section 2.3.1. Modal shapes are required to give an interpretation of the results obtained from the driving-point measurements. We make the hypothesis that the modal shapes and their order of appearance does not change between the guitars of the preliminary modal analysis on the mesh and the other guitars of the same model. In consequence, modes will be from now on refered to according to the mode numbering defined in the present section.

Table 1 shows the modal shapes, frequencies, and dampings for the six modes identified in the frequency bandwidth of the study on the analysed sample Type-1 guitar. 
Table 1: (colours online only) Results of the preliminary modal analysis carried out on one Type-1 guitar: mode shape (2 view angles are availables: the left one is a pseudo-3D view and the right one is a $2 \mathrm{D}$ view) and associated modal frequency and damping. For each mode, black dashed lines represent the steady state shape, red solid lines represent the mode shape.

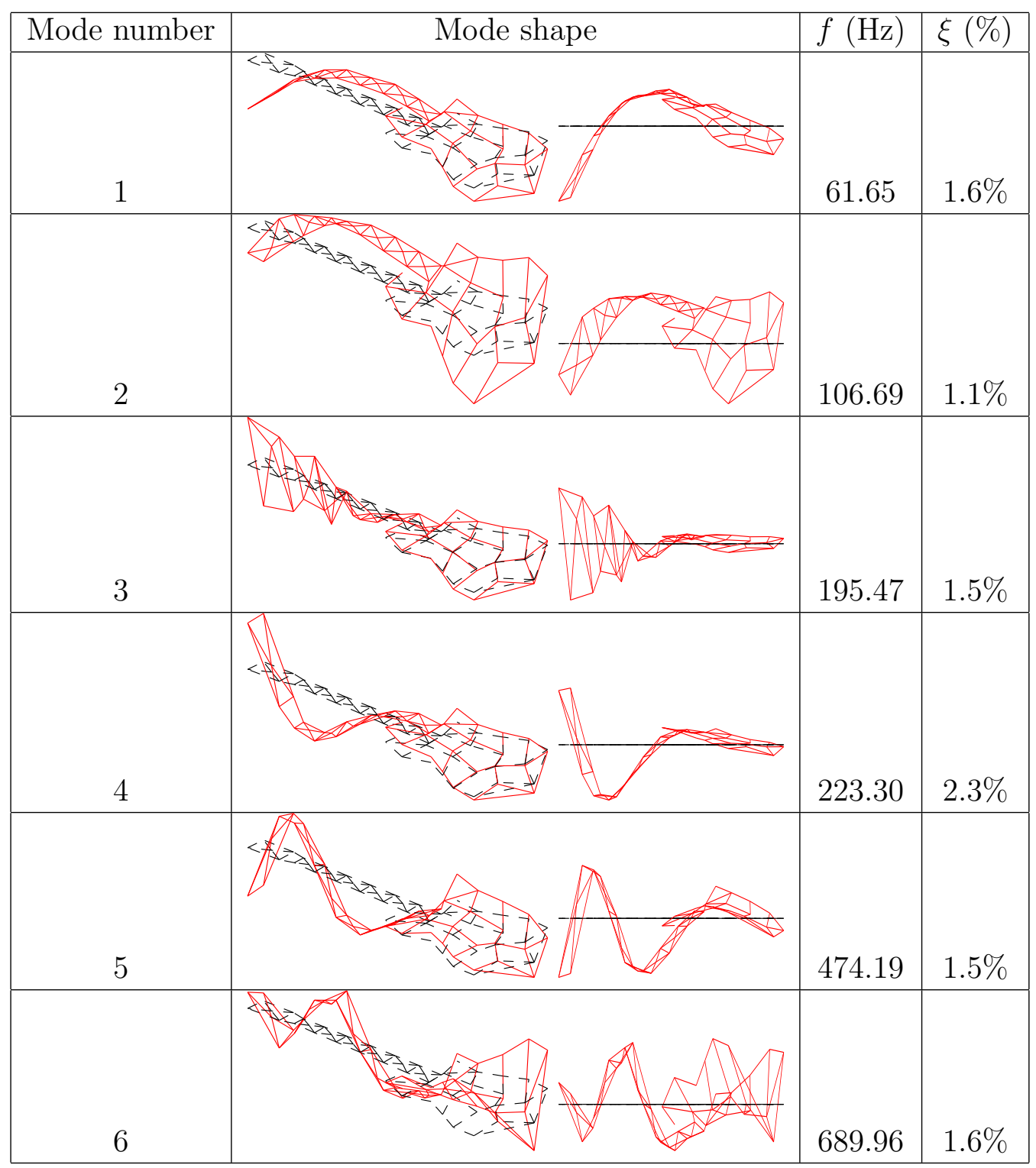

Table 2 shows the modal shapes, frequencies, and dampings for the six 
modes identified on the analysed sample Type-2 guitar in the frequency bandwidth of the study. All modes involving the neck in the frequency range of the study are well identified. 
Table 2: (colours online only) Results of the preliminary modal analysis carried out on one Type-2 guitar: mode shape (2 view angles are availables: the left one is a pseudo-3D view and the right one is a $2 \mathrm{D}$ view) and associated modal frequency and damping. For each mode, black dashed lines represent the steady state shape, red solid lines represent the mode shape.

\begin{tabular}{|c|c|c|c|}
\hline Mode number & Mode shape & $f(\mathrm{~Hz})$ & $\xi(\%)$ \\
\hline 1 & $E$ & 59.79 & $0.9 \%$ \\
\hline 2 & & 102.59 & $1.3 \%$ \\
\hline 3 & & 173.82 & $2.1 \%$ \\
\hline 4 & & 187.57 & $1.8 \%$ \\
\hline 5 & & 401.84 & $1.7 \%$ \\
\hline 6 & & 667.44 & $1.4 \%$ \\
\hline
\end{tabular}




\subsection{Mobility curves}

Figure 6 presents the driving-point mobility measurements for all guitars of the Type-1 set. Individual mobility curves are represented with thin gray lines. For each frequency bin, the mean and standard deviation of the 17 curves is computed. The mean mobility is plotted with a thicker black line. The gray area is the region bounded by 2 standard deviations below and above the mean mobility curve.

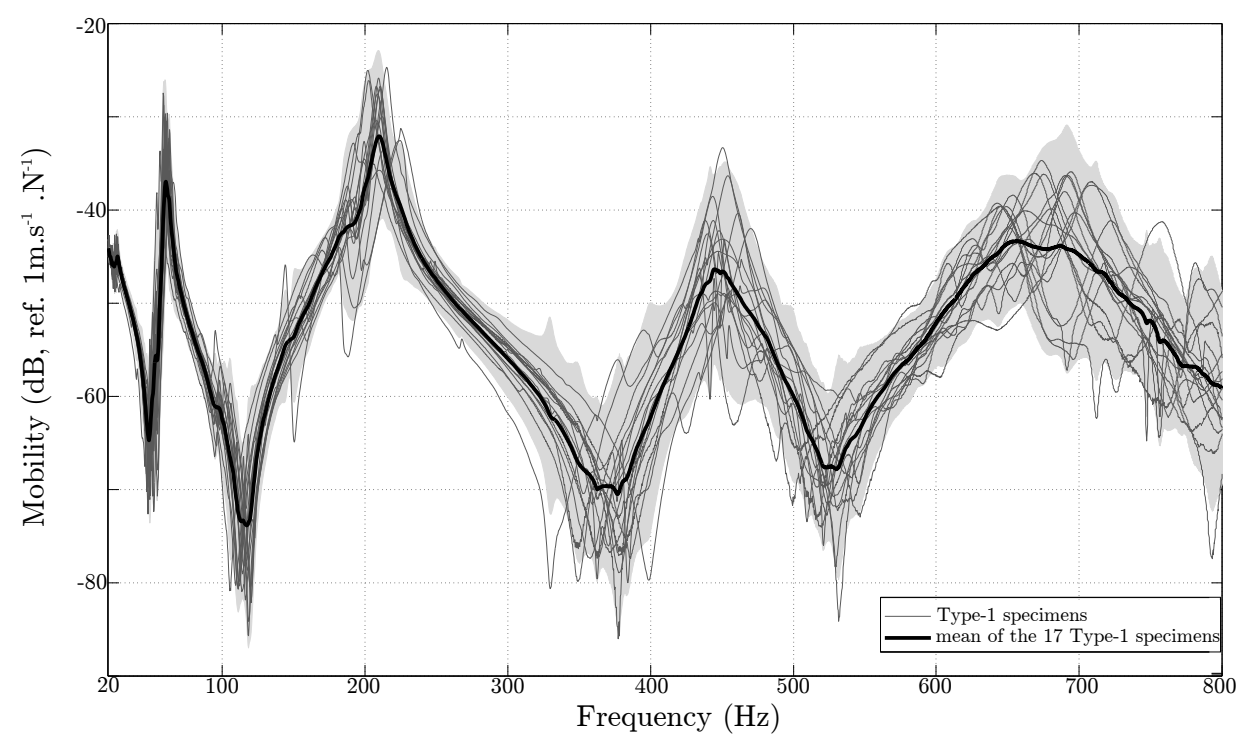

Figure 6: Superimposition of all mobility curves for the 17 Type-1 specimens. Individual mobility curves are represented with thin gray lines. The thick black line is the mean mobility. The gray area is centered on this mean mobility, and its boundaries are two standard deviation below and above the mean mobility.

Figures 7 and 8 present the driving-point mobility curves for the measurements on the Type-2 $R N$ and Type-2 $M N$ guitars respectively. Individual mobility curves are plotted with thin gray lines (dashed for the $R N$ guitars, and solid for the $M N$ guitars). Like for Type-1 guitars, means and standard deviations are computed for each frequency bin: the thicker red line (dashed for the $R N$ guitars, and solid for the $M N$ guitars) represents the mean of the mobility curves, and the gray area is the region bounded by 2 standard deviations below and above this mean mobility curve. The thick black solid line indicates the mean mobility of the whole 24-Type-2 set. 


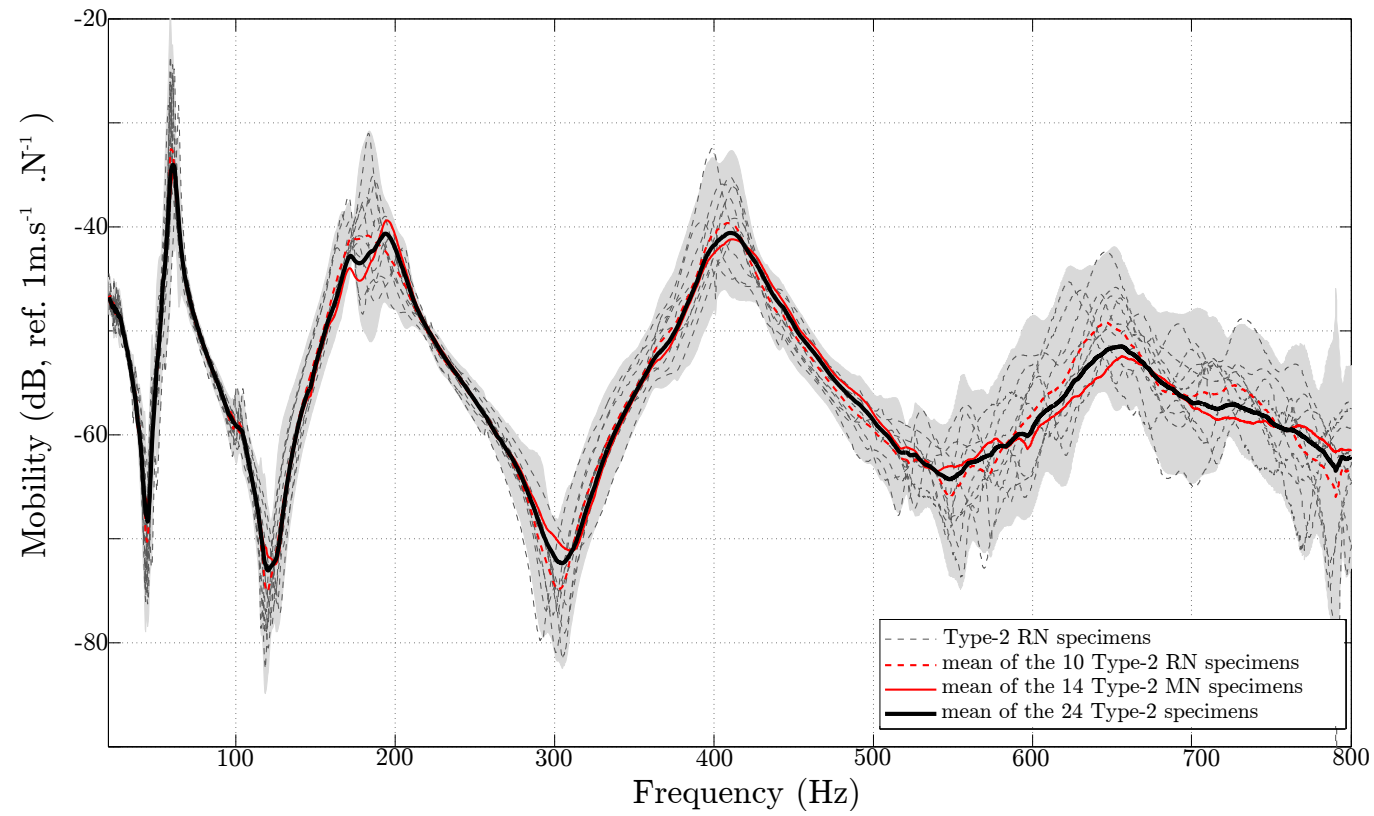

Figure 7: (colours online only) Superimposition of all mobility curves for the 10 Type-2 $R N$ specimens. Individual mobility curves are represented with thin dashed gray lines. The mean mobility of the 10 Type- $2 R N$ specimens is plotted with a dashed red line. The gray area is centered on this mean mobility, and its boundaries are two standard deviation below and above the mean mobility. The thick black line is the mean of the mobility curves of all 24 Type-2 guitars. For comparison purposes, the mean mobility of the 14 Type-2 $M N$ specimens is plotted with a solid red line. 


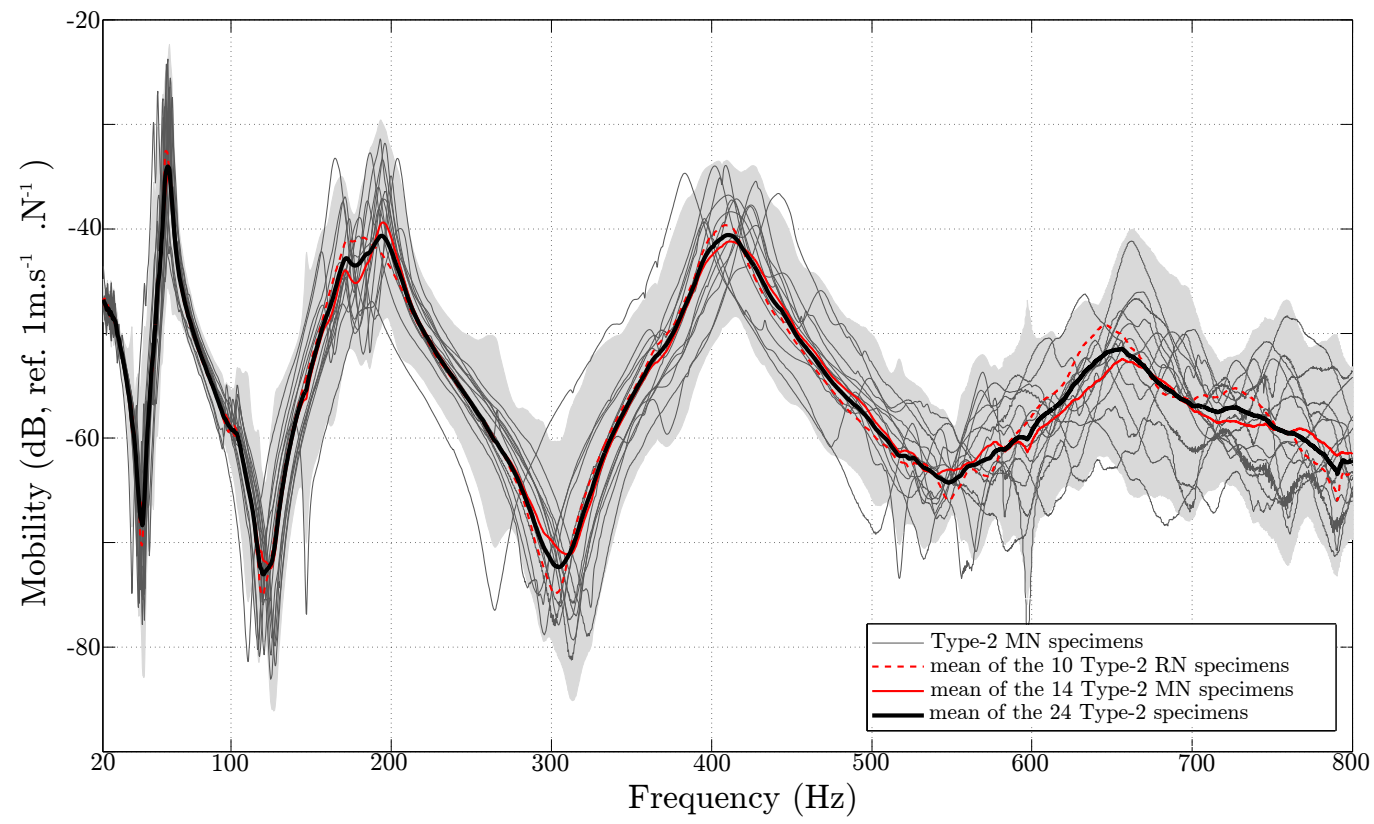

Figure 8: (colours online only) Superimposition of all mobility curves for the 14 Type-2 $M N$ specimens. Individual mobility curves are represented with thin solid gray lines. The mean mobility of the 14 Type-2 $M N$ specimens is plotted with a solid red line. The gray area is centered on this mean mobility, and its boundaries are two standard deviation below and above the mean mobility. The thick black line is the mean of the mobility curves of all 24 Type- 2 guitars. For comparison purposes, the mean mobility of the 10 Type-2 $R N$ specimens is plotted with a dashed red line.

Mobility curve superimpositions of figures 6,7 and 8 suggest the same qualitative remarks. Among one guitar set, all mobility curves have the same appearance: they follow the shape of the mean mobility curve. Looking a bit closer gives clues to identify differences between nominally identical guitars: mobility peak heights, peak locations (modal frequencies), or peak width seem to vary inside a set of nominally identical guitars. At this point, no clear trend is seen allowing to discriminate between the $R N$ and $M N$ guitars. It is noticed however that Type-2 $M N$ guitars show a higher variability than Type-2 $R N$ guitars: this could be due to the fact that one or two Type-2 $M N$ guitars stand out from the others. More quantitative comparisons can be obtained with the investigation of identified modal parameters. 


\subsection{Masses}

Figure 9 shows the masses of the guitars of the Type- 1 set. Each guitar is represented as a bar whose height is proportional to the guitar mass. The black solid line gives the mean mass $\mu_{m}$, and the black dashed lines give the area bounded by one standard deviation $\sigma_{m}$ below and one standard deviation below $\mu_{m}$. The 2-standard deviation spread around the mean is indicated as a percentage of the mean mass.

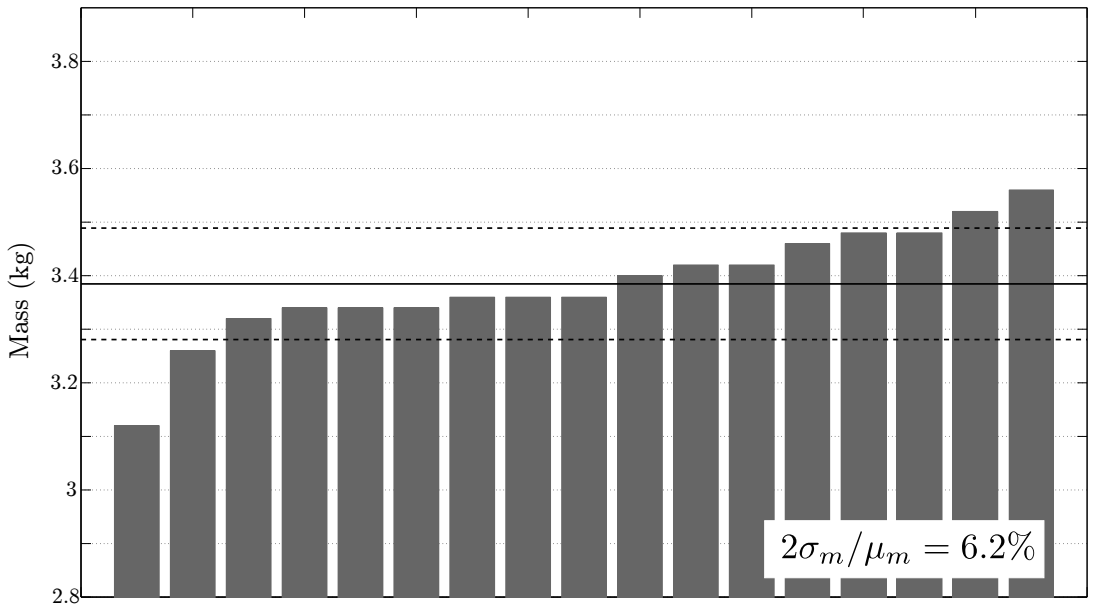

Type-1 guitars

Figure 9: Bar plot of the masses of the 17 Type-1 guitars. The black solid line indicates the mean mass $\mu_{m}$. The black dotted lines indicate the spread around the mean mass as 1 standard deviation below and above the mean mass: $\mu_{m} \pm \sigma_{m}$. The 2-standard deviation spread around the mean is indicated as a percentage of the mean mass.

Figure 10 shows the masses of the guitars of the Type-2 set. Light gray bars represent the $R N$ specimens and dark gray bars represent the $M N$ specimens. The mean mass values are represented by horizontal solid lines: black for the whole Type-2 set $\mu_{m}$, light gray for $R N$ guitars $\mu_{m, R N}$, and dark gray for $M N$ guitars $\mu_{m, M N}$. The spread around the mean mass is represented by dashed lines: black for the whole Type-2 set $\mu_{m} \pm \sigma_{m}$, light gray for $R N$ guitars $\mu_{m, R N} \pm \sigma_{m, R N}$, and dark gray for $M N$ guitars $\mu_{m, M N} \pm \sigma_{m, M N}$. The 2 -standard deviation spreads around the mean are indicated as a percentage of the mean mass. 


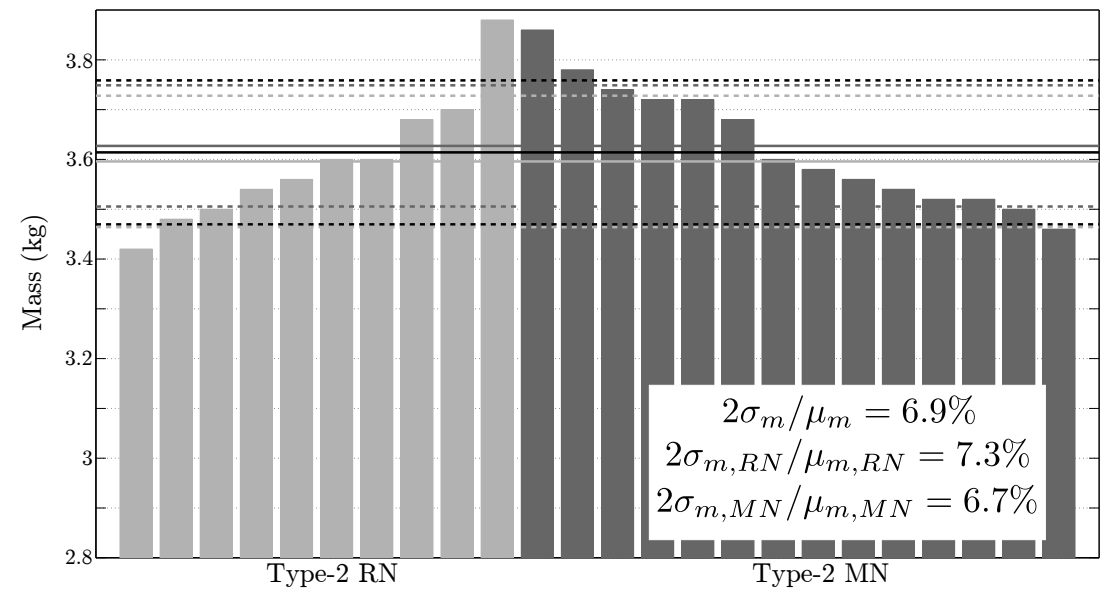

Figure 10: Bar plot of the masses of the 24 Type-2 guitars. The light (resp. dark) gray bars represent the $R N$ (resp. $M N$ ) specimens. The black, light gray, and dark gray solid lines indicate the mean mass $\mu_{m}$ of all 24 specimens, $\mu_{m, R N}$ of the $R N$ specimens, and $\mu_{m, M N}$ of the $M N$ specimens respectively. The black, light gray, and dark gray dashed lines indicate the quantity $\mu_{m} \pm \sigma_{m}$ of all 24 specimens, $\mu_{m, R N} \pm \sigma_{m, R N}$ of the $R N$ specimens, and $\mu_{m, M N} \pm \sigma_{m, M N}$ of the $M N$ specimens respectively. The 2 -standard deviation spreads around the means are indicated as a percentage of the corresponding mean mass.

Heavier (resp. lighter) guitars could be expected to have lower (resp. higher) modal frequencies. Nonetheless no such link between the mass of an individual instrument and its modal frequencies was observed on the two guitar sets. Three explanations can be found for that fact. First, the wood density (hence the mass) is certainly not the only parameter varying between two guitars: mechanical parameters such as Young's moduli, Poisson's ratios, or shear moduli are known to have non neglectible variations for nominally identical woods [31]. Second, modal frequencies also depend on the geometrical features of the guitars, so that variations in dimensions might sometimes counterbalance variations in mass. The aim of the study being the measurement and analysis of the vibratory characteristics of a large number of instruments, no geometrical measurements were done on the guitars, so no conclusion can be done about the respective influence of mass and geometry on the modal frequencies. And third, the modal masses are obviously related to the total mass of the guitar, but also to the mode shapes. The identified mode shapes seem to involve the neck more than the body, so that in terms of mass-dependence, the modal masses would rather depend on the mass variability of wood pieces used for the necks. This mass variability 
between necks may be not precisely rendered by the measurements of total guitar masses. Actually, the total masses ought to be determined rather by the "solid" body masses than by the neck masses.

\subsection{Modal frequencies}

Figure 11 shows the identified modal frequencies for the Type-1 guitars. For each mode, black crosses indicate the single modal frequencies, and a red cross indicates the mean value $\mu_{f}$ of the 17 single modal frequencies. The red circles indicate the spread of the modal frequencies, as 1 standard deviation $\sigma_{f}$ below and above the mean value: $\mu_{f} \pm \sigma_{f}$. This spread $2 \sigma_{f}$ is expressed as a percentage of $\mu_{f}$ with the red numbers beside the mean frequencies. The variability $2 \sigma_{f} / \mu_{f}$ is quite consistent among modes. Note that the modes with the lowest modal frequency variability are the neck bending modes numbered 4,5 , and 6 . Highest $2 \sigma_{f} / \mu_{f}$ values are reached for modes involving a neck torsion (2 and 3). This higher variability for torsional modes may be explained by the angle of the wood cut, to which the torsional behaviour of the neck may be very sensitive. Here the Type-1 guitars have a quartersawn rosewood fingerboard glued to a quartersawn mahogany neck, the $R N$ guitars have a quartersawn rosewood fingerboard glued to a flatsawn maple neck, and the $M N$ guitars have a quartersawn maple fingerboard glued to a flatsawn maple neck. There is some tolerance upon the wood cut angle of each wood piece. The assembling of two wood pieces (fingerboard and neck), both with uncertainties in the wood cut angle, may by a factor of variation in the torsional behaviour of the necks. Furthermore the tree trunks are known to undergo torsional pre-stress during their growth. This could alter the torsional behaviour of the necks. 


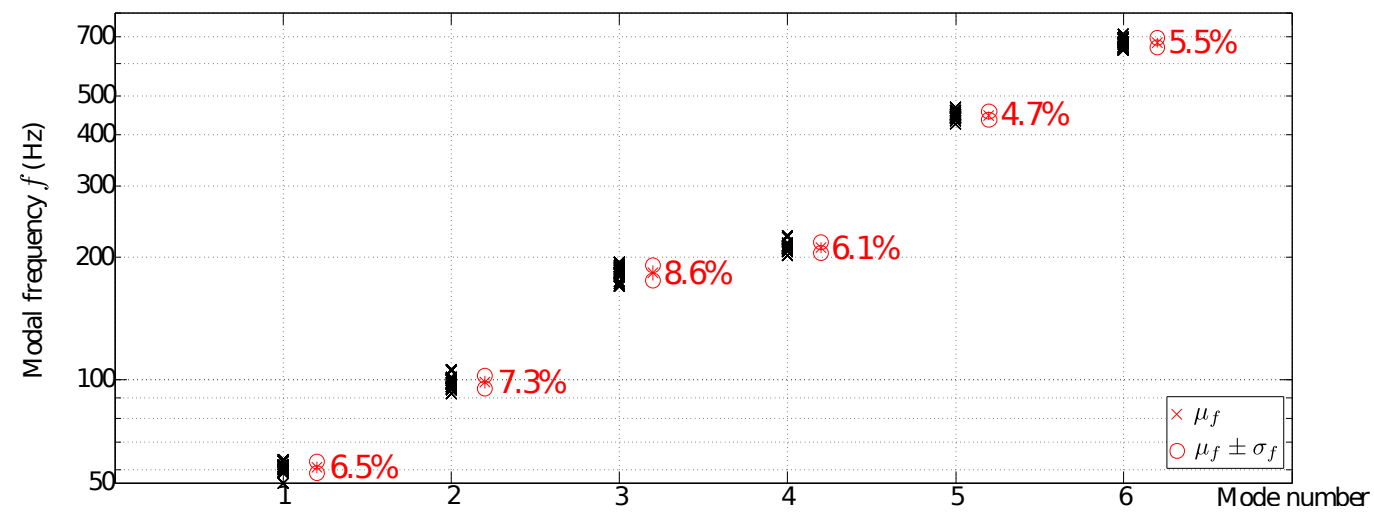

Figure 11: (colours online only) Identified modal frequencies for the 17 Type-1 specimens. For each mode, the black crosses indicate the single modal frequencies. For each mode, the red crosses indicate the mean value $\mu_{f}$ of the 17 modal frequencies. The red circles indicate the spread of the modal frequencies, as 1 standard deviation below and above the mean value: $\mu_{f} \pm \sigma_{f}$. Red numbers indicate the value $\sigma_{f} / \mu_{f}$.

Figure 12 shows the identified modal frequencies for the Type-2 guitars. For each mode, the left (resp. right) cluster of black crosses indicates the individual modal frequencies for the $R N$ (resp. $M N$ ) guitars. Associated with each black cross cluster is the corresponding mean value $\mu_{f, R N}$ or $\mu_{f, M N}$ (isolated black cross), and spread around the mean value $\mu_{f, R N} \pm \sigma_{f, R N}$ or $\mu_{f, M N} \pm \sigma_{f, M N}$ (black circles). For each mode, the red cross indicates the mean value $\mu_{f}$ of the 24 single modal frequencies (the whole Type-2 set), and the red circles indicate the corresponding modal frequency spread $\mu_{f} \pm \sigma_{f}$. This spread $2 \sigma_{f}$ (resp. $2 \sigma_{f, R N}$ and $2 \sigma_{f, M N}$ ) is expressed as a percentage of $\mu_{f}$ (resp. $\mu_{f, R N}$ and $\left.\mu_{f, M N}\right)$ with the red (resp. black) numbers beside the frequency clusters. Just as in the case of the Type-1 guitars, the frequency variability for the whole set of Type-2 is consistent for all modes. The frequency variability within the two subsets is a bit less consistent: the $R N$ subset shows frequency variations from $3.1 \%$ (mode 2 ) to $8.4 \%$ (mode 3 ), and the $M N$ subset from $5.5 \%$ (mode 6 ) to $9.0 \%$ (mode 1 ). This time, it is not clear whether neck torsional modes tend to have higher frequency variabilities $2 \sigma_{f} / \mu_{f}$ : mode 3 have a shape very similar to mode 4 , but with additional torsional motion of the headstock. Both modes show comparable frequency variabilities. 


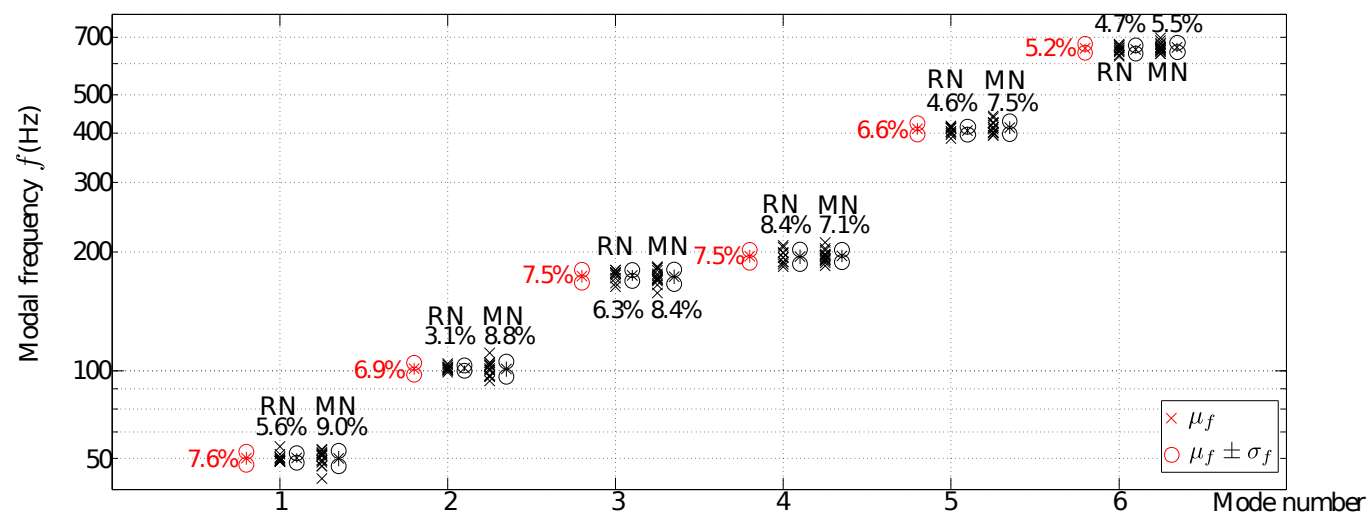

Figure 12: (colours online only) Identified modal frequencies for the 24 specimens Type-2. Black crosses indicate the individual modal frequencies. For each modal frequency, the red crosses indicate the mean value $\mu_{f}$ of the 24 identified frequencies, and the red circles indicate the spread of the modal frequencies, as 1 standard deviation below and above the mean value: $\mu_{f} \pm \sigma_{f}$. For each mode, the two black crosses clusters refer to the modal frequencies of the $R N$ guitars, and $M N$ guitars, from left to right. Associated with each cluster is the corresponding mean value, and spread around the mean value. Red (resp. black) numbers indicate the value $\sigma_{f} / \mu_{f}\left(\right.$ resp. $\sigma_{f, R N} / \mu_{f, R N}$ and $\left.\sigma_{f, M N} / \mu_{f, M N}\right)$.

\subsection{Modal damping ratios}

Figure 13 shows the identified modal damping ratios for the Type-1 guitars. Black crosses indicate the single modal damping ratios, and a red cross indicates the mean damping ratio $\mu_{\xi}$ for each mode. The red circles indicate the spread of the modal damping ratios $\mu_{\xi} \pm \sigma_{\xi}$. This spread $2 \sigma_{\xi}$ is expressed as a percentage of $\mu_{\xi}$ with the red numbers beside the mean frequencies. 


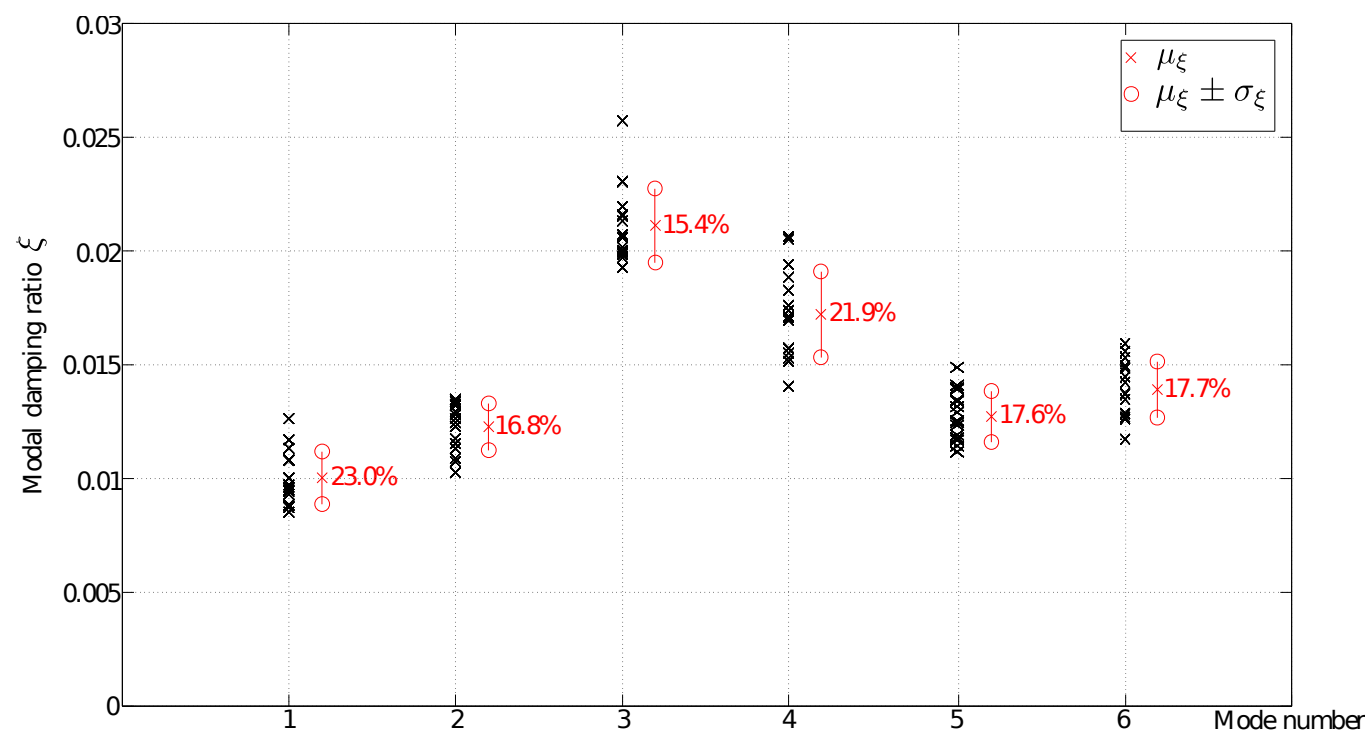

Figure 13: (colours online only) Identified modal damping ratios for the 17 Type-1 specimens. For each mode, the black crosses indicate the single modal damping ratios. For each mode, the red crosses indicates the mean value $\mu_{\xi}$ of the 17 modal damping ratios. The red circles indicate the spread of the modal damping ratios around the mean value, as 1 standard deviation below and above the mean value: $\mu_{\xi} \pm \sigma_{\xi}$. Red numbers indicate the value $\sigma_{\xi} / \mu_{\xi}$.

The two first modes involving a motion of the whole guitar show similar damping ratios. Modes 5 and 6 , which are neck bending mode with or without body motion have analogous damping ratios. Mode 4 has slightly higher damping ratios. Neck and headstock torsional mode 3 significantly stands out from the others with a much higher damping ratio. The inter-variability in damping ratio keeps very stable from one mode to another.

Figure 14 shows the identified modal damping ratios for the Type-2 guitars. For each mode, the left (resp. right) cluster of black crosses indicates the single modal damping ratios for the $R N$ (resp. $M N$ ) guitars. Each cluster is associated with its mean value $\mu_{\xi, R N}$ or $\mu_{\xi, M N}$ (isolated black cross) and spread around the mean value $\mu_{f, R N} \pm \sigma_{f, R N}$ or $\mu_{f, M N} \pm \sigma_{f, M N}$ (black circles). For each mode, the red cross indicates the mean value $\mu_{\xi}$ for the whole Type-2 set, and the red circles indicate the corresponding spread $\mu_{\xi} \pm \sigma_{\xi}$. The red (resp. black) numbers beside the clusters express the quantity $2 \sigma_{\xi}$ (resp. $2 \sigma_{\xi, R N}$ and $\left.2 \sigma_{\xi, M N}\right)$ as a percentage of $\mu_{\xi}\left(\right.$ resp. $\mu_{f, R N}$ and $\mu_{f, M N}$ ). 


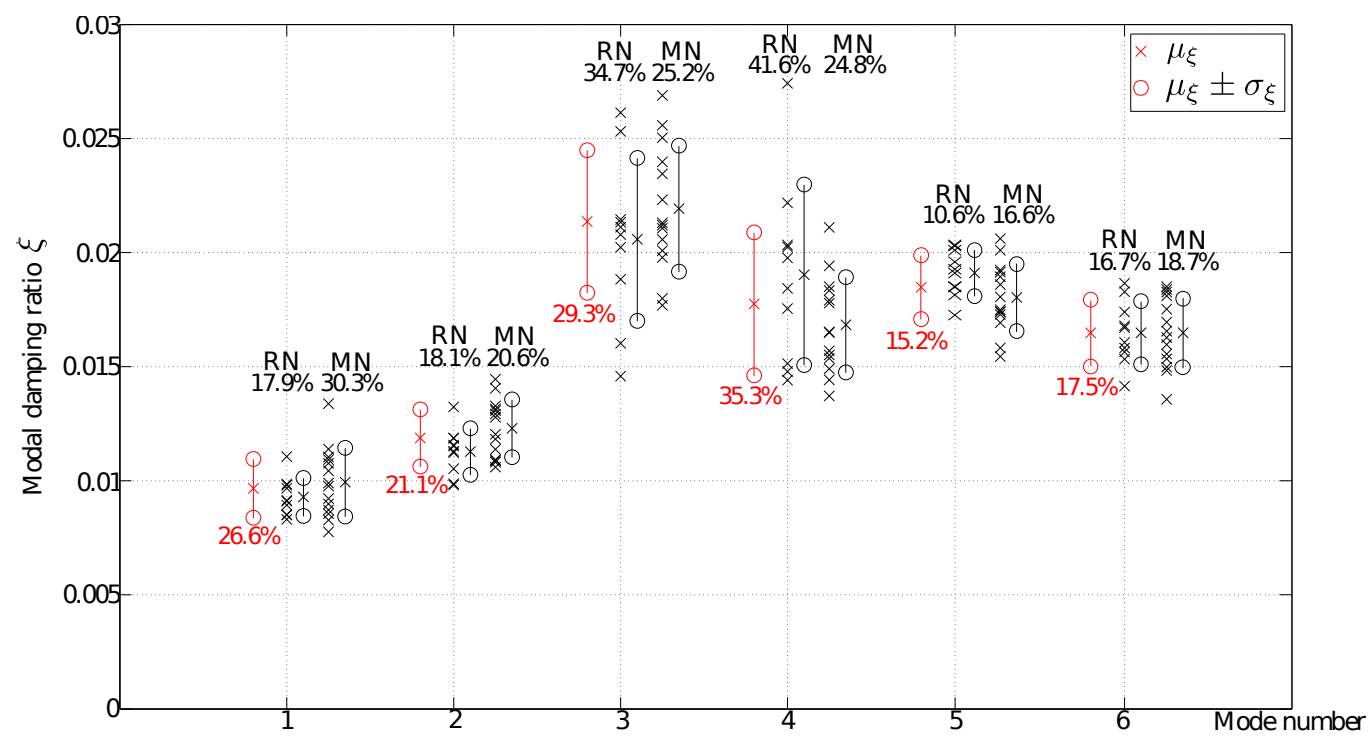

Figure 14: (colours online only) Identified modal damping ratios for the 24 Type-2 specimens. Black crosses indicate the individual modal damping ratios. For each modal damping ratio, the red crosses indicate the mean value $\mu_{\xi}$ of the 24 identified damping ratios, and the red circles indicate the spread of the modal damping ratios, as 1 standard deviation below and above the mean value: $\mu_{\xi} \pm \sigma_{\xi}$. For each mode, the two black cross clusters refer to the modal damping ratios of the $R N$ guitars, and the $M N$ guitars, from left to right. Associated with each cluster is the corresponding mean value, and spread around the mean value. Red (resp. black) numbers indicate the value $\sigma_{\xi} / \mu_{\xi}\left(\right.$ resp. $\sigma_{\xi, R N} / \mu_{\xi, R N}$ and $\left.\sigma_{\xi, M N} / \mu_{\xi, M N}\right)$.

Just like Type-1 guitars, the two first modes (which are whole guitar modes) of the Type-2 set have significantly lower damping ratios. A level higher are the modes 4 to 6 (which involve both body motion, but more importantly neck modes with beam-like shapes). Like the 3rd mode of the Type-1 guitars, the 3rd mode of the Type-2 guitars involves headstock torsion and seems to have a higher mean damping ratio. However, the facts that the damping ratio variability for the 3rd Type-2 mode is about two times higher than for the 3rd Type-1 mode makes this tendency not as clear as for Type-1 guitars. The whole Type-2 set shows variability values $\sigma_{\xi} / \mu_{\xi}$ of the same order of magnitude as the Type-1 set for modes 1, 5, and 6. For other modes, the variability in damping ratio is higher for the Type-2 set.

Section 4 first sums up the modal parameter variability order of magnitudes obtained on the present large sets of industrial electric guitars and 
compares it to results from the literature obtained with other industrial products. The discussion is then turned towards the comparison between the variability originating from the making process and the variability due to an intentional lutherie change: the fingerboard wood.

\section{Discussion}

This section discusses the modal parameter variabilities presented in section 3. First they are compared to the variability reported for other industrial objects, and then a comparison between intra-group and inter-group variabilities attempts to tell apart two causes of variability: that due to the making process (including the wood selection) and that due to an intentional lutherie decision like the wood of the fingerboard.

\subsection{Modal parameter variability for electric guitar as industrial objects}

Investigations on three guitar sets (Type-1, Type-2 RN, and Type-2 MN) give a good overview of the modal parameter variation for nominally identical electric guitars. In terms of modal frequency, the spread $2 \sigma_{f} / \mu_{f}$ takes values from $3.1 \%$ to $9.0 \%$. For purposes of comparison, this modal parameter spread can be expressed in terms of variation range. For a given mode, the variation range of a modal parameter is defined as the difference between the maximum and the minimum values within the set: the modal frequency variation range is defined as $\Delta_{f}=f_{\max }-f_{\min }$ and the modal damping ratio variation range as $\Delta_{\xi}=\xi_{\max }-\xi_{\min }$. These variation ranges are given in table 3 as percentages of the mean value for the corresponding guitar set. 
Table 3: Variation ranges of modal frequencies $\Delta_{f}$ and damping ratios $\Delta_{\xi}$, for each mode and each guitar set/subset. $\Delta_{f}$ and $\Delta_{\xi}$ are given as percentages of the mean values $\mu_{f}$ and $\mu_{\xi}$ of the corresponding guitar set.

\begin{tabular}{|c|c|c|c|c|c|c|c|}
\hline & mode & 1 & 2 & 3 & 4 & 5 & 6 \\
\cline { 2 - 8 }$\Delta_{f}=f_{\text {max }}-f_{\text {min }}$ & Type-1 & $13.2 \%$ & $13.8 \%$ & $13.6 \%$ & $11.4 \%$ & $9.6 \%$ & $9.2 \%$ \\
\cline { 2 - 8 } & all Type-2 & $18.3 \%$ & $16.5 \%$ & $15.1 \%$ & $14.2 \%$ & $13.4 \%$ & $10.8 \%$ \\
& Type-2 $R N$ & $9.0 \%$ & $5.1 \%$ & $9.5 \%$ & $12.5 \%$ & $7.3 \%$ & $7.1 \%$ \\
& Type-2 $M N$ & $16.6 \%$ & $16.5 \%$ & $15.2 \%$ & $13.7 \%$ & $11.5 \%$ & $9.4 \%$ \\
\hline \hline \multirow{3}{*}{$\Delta_{\xi}=\xi_{\text {max }}-\xi_{\min }$} & mode & 1 & 2 & 3 & 4 & 5 & 6 \\
\cline { 2 - 8 } & Type-1 & $41.0 \%$ & $26.2 \%$ & $30.5 \%$ & $38.3 \%$ & $29.1 \%$ & $30.2 \%$ \\
\cline { 2 - 8 } & all Type-2 & $58.1 \%$ & $39.0 \%$ & $57.6 \%$ & $77.2 \%$ & $28.0 \%$ & $30.9 \%$ \\
& Type-2 RN & $29.6 \%$ & $30.3 \%$ & $56.1 \%$ & $68.4 \%$ & $16.1 \%$ & $27.4 \%$ \\
& Type-2 MN & $56.6 \%$ & $31.4 \%$ & $42.0 \%$ & $43.9 \%$ & $28.7 \%$ & $29.9 \%$ \\
\hline
\end{tabular}

$\Delta_{\xi}$ values range from $16.1 \%$ to $77.2 \%$ for the sets of nominally identical electric guitars of the present study, and from $4.0 \%$ to $140.0 \%$ (most of the values lying from $20 \%$ to $50 \%$ ) for the study of the wind turbine blades [20]. It is noticed that electric guitars present less varying modal damping than other industrial objects. Modal dampings are consistent for nominally identical electric guitars, that means that the spread of the conductance peaks partly responsible for string/structure coupling is a parameter that is quite well controlled by the guitar manufacturers.

For sets of nominally identical guitars, $\Delta_{f}$ values range from $5.1 \%$ of $\mu_{f}$ (Type-2 $R N$ ) up to $16.6 \%$ (Type-2 $M N$ ). The study of two nominally identical wind turbine blades [20] reports modal frequency differences ranging from $0.1 \%$ to $1.7 \%$. The study of more than a hundred brake calipers [21] reports a maximum modal frequency deviation of $5 \%$. Theses two results obtained on industrial objects can be compared to the present results, because they express a variation range as a percentage of the mean. Electric guitars show higher frequency variations than other industrial objects. This seems reasonable, for at least two reasons. First, even if many manufacturing steps of the electric guitars of the study are automated, some steps involve handwork: shaping of the neck profile, fretting the fingerboard, joining the neck to the body, etc. This may be a cause of inter-objects variation. Second, the brake calipers [21] are made of aluminium alloy and the wind turbine blade [20] of plastic and carbon fibres, whereas the electric guitars of the present study are made of wood. Wood is a material that is known for showing a 
quite large variability in mechanical parameters [31, 32]. This may result in the larger frequency variability observed for the guitars in comparison to the other industrial objects. This uncertainty about the conductance peak location for two nominally identical guitars may explain partly the difference felt by the guitar players when testing several guitars of the same model. The vibratory characteristics of each specimen lie somewhere within the variation range imposed by the model specifications: this make each guitar have both proper sound characteristics and shared common features with other guitars of the same model.

\subsection{Lutherie change vs. making process: influence on the modal parameter variability}

The typical modal parameter intra-variability within a set of nominally identical guitars can be identified considering the Type-1, Type-2 RN, and Type-2 $M N$ set. The two latter sets can also be compared one to another in order to get information about the amount of variability caused by an intentional lutherie change.

Figure 12 shows that for each mode the mean frequencies of the subsets $\mu_{f, R N}$ and $\mu_{f, M N}$ are very similar. Both are extremely close to the mean modal frequency $\mu_{f}$ of the whole Type-2 set. Furthermore, the frequency spreads $2 \sigma_{f, R N}$ and $2 \sigma_{f, M N}$ around the mean values strongly overlap. This means that no significant difference in modal frequency is observed between $R N$ (rosewood fingerboard) and $M N$ (maple fingerboard) guitars. A trend can however be noticed: except for mode 4 , the $M N$ subset exhibits higher variability than the $R N$ subset. The same trend is noticed without exception in table 3. Every piece of wood that the manufacturer buys is systematically stored for months in a dry place, in order to guarantee the highest possible stability for the woods, before the making process starts. The maple used for the present guitars comes either from the United States or Canada, whereas the rosewood comes from India. Because of the very large number of guitars produced by the manufacturer, various wood suppliers are involved. The factories are located in North-America. On the one hand, a higher wood variability is expected for the wood that travelled the most (rosewood), because of climate, temperature, hygrometry changes. On the other hand, maple is known by luthiers to be a less stable wood than rosewood, that is to say it could be subject to higher strain (caused by the pre-stress due to the wood history). This latter fact may be of greater influence than the former, explaining the slightly higher variability noticed for $M N$ guitars. 
Differences in mean damping ratios can be found between $R N$ and $M N$ guitars in figure 14: $\mu_{\xi, M N}$ is higher than $\mu_{\xi, R N}$ for modes 1,2 , and 3 , whereas the contrary holds for modes 4 , and $5 . \mu_{\xi, R N}$ and $\mu_{\xi, M N}$ have almost exactly the same value for mode 6 . These differences are however not significant, since the bars representing the spread $2 \sigma_{\xi, R N}$ and $2 \sigma_{\xi, M N}$ around the corresponding mean values tightly overlap. Figure 14 and table 3 do not show any trend in terms of modal damping variability between the two Type-2 subsets: no subset consistently exihibits higher damping ratio variability.

In the end, nor higher neither significantly different modal parameter variability is found between two sets of guitars differing in a single intentional lutherie parameter (here the fingerboard wood) than within sets of nominally identical guitars. This could mean that the main cause of modal parameter variability for electric guitars is rather the making process or the intrinsic variability of the wood than an intentional lutherie change like the wood of the fingerboard.

\section{Conclusion}

Vibratory measurements have been carried out on different sets of industrially-made guitars. The first set is made of 17 nominally identical Type- 1 guitars. The second set contains 24 Type-2 guitars, that are to be further split into two subsets according to the only intentional difference: a subset is made of 10 guitars with a rosewood fingerboard $(R N)$, and the second subset is made of 14 guitars with a maple fingerboard $(M N)$. The measurements have been analysed in order to identify the modal frequencies and dampings of each guitar in the low-frequency range.

The study of the Type-1, Type-2 RN, and Type-2 MN sets, each grouping together nominally identical guitars, allows to quantify the typical variability in modal frequency and damping ratio due to the making process and the wood intrinsic variability. This study is the first of its kind for industriallymade electric guitars. Typical variability in modal frequencies are shown to be higher for the electric guitars of the present study than for other industrial products. Note that if a generalisation of this conclusion undoubtedly requires more measurements on other guitars from different manufacturers, the trends observed here may be found on other sets of indutrial guitars, since the present manufacturer's methods are thought to be quite typical of the tradition of industrial electric guitar making. This higher variability in modal frequencies for guitars may have two explanations: first the manufacturing 
process of electric guitars still involves handwork critical tasks (fretting the fingerboard, joining neck and body, adjusting the whole guitar), which is in general not the case for industrial objects. Second, like many string instruments, the electric guitar is made of wood, a quite varying material. Typical modal damping ratio variability in electric guitars has been found to be quite high, but it is much more consistent than for other industrial products, when comparing the different modes one with another. It could mean that the spread of the conductance peaks (determined by the modal damping) partly responsible for the string/structure coupling is a parameter that is quite well controlled by the guitar manufacturers.

The Type-2 $R N$ and Type-2 $M N$ sets are expected to differ only in one lutherie parameter: the wood of the fingerboard. The modal frequency and damping ratio differences between these two sets are then expected to be mainly due to this lutherie change. None of these guitar sets stands out from the other, and no higher variability is noticed between intentionally different guitars ( $R N$ and $M N$ guitars) than between two nominally identical guitars (guitars from the same set).

Modal frequency and damping ratio are important for the description of the string/structure coupling. They can explain sound differences related to energy losses from the string's point of view. But they strongly depend on coincidences that might occur between string playing frequencies and structure frequencies. In the general case, such a coincidence does not occur so clearly, and other mechanical features than modal frequency and damping ratio may be more appropriate for characterising the influence of the structure on the sound. The use of mean conductance values has been proposed in a previous study for the discrimination between ebony and rosewood fingerboards [24]. For the guitars of the present study, this mechanical parameter did not give clear results, so future work should concentrate on finding other mechanical parameters allowing to render the difference between maple and rosewood fingerboards. The modal masses have been discarded from this study. A future study should investigate these parameters, since they also participate in the string/structure coupling [3].

An important thing to be noted is that a high variability or variation range means in no case an impaired making process, or non-reliable guitars. This variability is rather to be seen as a chance. Different guitars of the same model share common properties, that are imposed by the specifications of the model. But each of them also has its own characteristics. Within the Type2 family, a $R N$ guitar and a $M N$ guitar share some properties, and some 
features are not common to the two guitars. Some properties are likely due to the fingerboard wood, and some of these may be compensated by other features. Many guitar players have a holistic approach to the guitar: the instrument is perceived and evaluated as a whole. This may be why guitar players often test several guitars before purchasing one, or why they can play many guitars of the same model for many different purposes, music styles, etc. Nowadays many phenomena are explained by scientific investigations, but some lutherie subtleties still escape the mechanical modelling.

This study has focused on modal parameters, so have been restricted to the modal domain, that only covers the frequency range called bass of low-mids by the players. The study should then be completed with a vibratory characterisation and comparison of the guitars in the mid- and highfrequency domain, with the use of other descriptors like for example mean mobility or mobility envelope curves [28, 33].

\section{Acknowledgements}

A very special and warm thank goes to everyone from the electric guitar manufacturing company. Thanks to Benoît Navarret, Gary Scavone, Claudia Fritz, Marcelo Wanderley, and Hossein Mansour for fruitful discussions.

[1] A. Paté, B. Navarret, R. Dumoulin, J.-L. Le Carrou, B. Fabre, and V. Doutaut. About the electric guitar: a cross-disciplinary context for an acoustical study. In Proceedings of Acoustics 2012, pages 1-6, Nantes (France), 2012.

[2] C. Valette. The mechanics of vibrating strings. In A. Hirschberg, J. Kergomard, and G. Weinreich, editors, Mechanics of musical instruments, pages 115-183. Springer Verlag, Wien - New York City, 1995.

[3] C. E. Gough. The theory of string resonances on musical instruments. Acustica, 49:124-141, 1981.

[4] N. H. Fletcher. Analysis of the design and performance of harpsichords. Acustica, 37:139-147, 1977.

[5] J. Woodhouse. On the synthesis of guitar plucks. Acta Acustica united with Acustica, 90:928-944, 2004. 
[6] H. Fleischer and T. Zwicker. Mechanical vibrations of electric guitars. Acta Acustica united with Acustica, 84:758-765, 1998.

[7] H. Fleischer and T. Zwicker. Investigating dead spots of electric guitars. Acta Acustica united with Acustica, 85:128-135, 1999.

[8] A. Paté, J.-L. Le Carrou, and B. Fabre. Predicting the decay time of solid body electric guitar tones. The Journal of the Acoustical Society of America, 135(5):3045-3055, may 2014.

[9] J. Meyer. Quality aspects of the guitar tone. In E. V. Jansson, editor, Function, constuction and quality of the guitar, pages 51-76. KTH, Stockholm (Sweden), 1983.

[10] J. Meyer. The function of the guitar body and its dependence upon constructional details. In E.V. Jansson, editor, Function, constuction and quality of the guitar, pages 76-94. KTH, Stockholm (Sweden), 1983.

[11] A. Mamou-Mani and D. B. Sharp. Evaluating the suitability of acoustical measurement techniques and psychophysical testing for studiying the consistency of musical wind instrument manufacturing. Applied Acoustics, 71:668-674, 2010.

[12] A. Mamou-Mani, D. B. Sharp, T. Meurisse, and W. Ring. Investigating the consistency of woodwind instrument manufacturing by comparing five nominally identical oboes. The Journal of the Acoustical Society of America, 131 (1):728-736, 2012.

[13] R. J. Bernhard. The limits of predictability due to manufacturing and environmentally induced uncertainty. In Proceedings of Inter-Noise 96, pages 2867-2872, Liverpool (United Kingdom), 1996.

[14] J.-L. Guyader and E. Parizet. Uncertainty of vibroacoustic behaviour of industrially identical structures. a new challenge for structural acoustic people. In Proceedings of the 5th international congress on sound and vibration (ICSV), Adelaide (Australia), 1997.

[15] J.-F. Durand, C. Soize, and L. Gagliardini. Structural-acoustic modeling of automotive vehicles in presence of uncertainties and experimental identification and validation. The Journal of the Acoustical Society of America, 124 (3):1513-1525, 2008. 
[16] G. Borello, L. Gagliardini, and D. Thenail. Virtual statistical energy analysis for vibroacoustic industrial prediction. The Journal of the Acoustical Society of America, 123(5):3314-3314, 2008.

[17] L. Gagliardini, J.-F. Durand, and C. Soize. Stochastic modeling of the vibroacoustic behavior of production cars. The Journal of the Acoustical Society of America, 123(5):3533-3533, 2008.

[18] E. Hills, B. R. Mace, and N. S. Ferguson. Acoustic response variability in automotive vehicles. Journal of Sound and Vibration, 321:286-304, 2008 .

[19] R. Bernhard and M. Kompella. Measurement of the statistical variation of structural-acoustic characteristics of automotive vehicles. SAE, 12:6581, 1993.

[20] D. T. Griffith, M. Casias, and G. Smith. Experimental uncertainty quantification of a class of wind turbines blades. In Proceedings of IMACXXIV, pages 1-16, Saint-Louis, Missouri, 2006.

[21] A. Gallina, W. Lisowski, L. Pichler, A. Stachowski, and T. Uhl. Analysis of natural frequency variability of a brake component. Mechanical Systems and Signal Processing, 32:188-199, 2012.

[22] J.-L. Le Carrou, J. Frelat, A. Mancel, and B. Navarret. Guitare électrique: quel rôle pour les éléments de lutherie ? In Proceedings of the 10e Congrès Français d'Acoustique (10th French Congress on Acoustics), pages 1-6, Lyon, France, 2010.

[23] A. Paté, J.-L. Le Carrou, B. Navarret, D. Dubois, and B. Fabre. A vibro-acoustical and perceptive study of the neck-to-body junction of a solid-body electric guitar. In Proceedings of Acoustics 2012, pages 1-6, Nantes (France), 2012.

[24] A. Paté, J.-L. Le Carrou, and B. Fabre. Ebony vs rosewood: experimental investigation about the influence of the fingerboard on the sound of a solid body electric guitar. In Proceedings of the Stockholm Musical Acoustics Conference (SMAC), pages 182-187, Stockholm (Sweden), 2013. 
[25] D. J. Ewins. Modal testing: theory and practice. Research studies press Ltd., John Wiley \& sons, 1984.

[26] J. Piranda. Analyse modale expérimentale. Techniques de l'ingénieur Mesures acoustiques et vibratoires, TIB420DUO(R6180), 2001.

[27] R. Roy, A. Paulraj, and T. Kailath. Esprit: A subspace rotation approach to estimation of parameters of cisoids in noise. IEEE transactions on acoustics, speech, and signal processing, 34:1340-1342, 1986.

[28] B. Elie, F. Gautier, and B. David. Macro parameters describing the mechanical behavior of classical guitars. The Journal of the Acoustical Society of America, 132:4013-4024, 2012.

[29] B. Elie, F. Gautier, and B. David. Estimation of mechanical properties of panels based on a modal density and mean mobility measurements. Mechanical systems and signal processing, 40:628-644, 2013.

[30] J.-L. Le Carrou, F. Gautier, and R. Badeau. Sympathetic string modes in the concert harp. Acta Acustica united with Acustica, 95:744-752, 2009 .

[31] D.E. Kretschmann. Mechanical properties of wood (chapter 5). In C.D. Risbrudt, M.A. Ritter, and T.H. Wegner, editors, Wood Handbook: Wood as an Engineering Material, page 100. USDA Forest Service - Forest Products Laboratory, Madison, WI, 2010.

[32] D. Guitard. Mécanique du matériau bois et composites (Mechanics of wood and composites). Collection Nabla. Cépaduès éditions, 1987.

[33] E. Skudrzyk. The meanvalue method of predicting the dynamic response of complex vibrators. The Journal of the Acoustical Society of America, 67(4):1105-1135, 1980. 